\title{
Prevalence and factors associated with dental erosion in individuals aged $12-30$ years in a northeastern Brazilian city
}

This article was published in the following Dove Press journal:

Clinical, Cosmetic and Investigational Dentistry

16 October 2017

Number of times this article has been viewed

\author{
Luanda Cristina O Luciano' \\ Meire Coelho Ferreira ${ }^{2}$ \\ Marco Aurelio Paschoal ${ }^{2}$ \\ 'Dentistry Program, Facimp Devry, \\ Imperatriz, ${ }^{2}$ Post Graduate Program \\ in Dentistry, CEUMA University, São \\ Luís, Brazil
}

Background/Purpose: Dental erosion in young individuals has increased significantly in recent years, due to changes in lifestyle. Thus, the present study investigated the prevalence and factors associated with dental erosion in individuals aged 12-30 years in the city of Imperatriz of Maranhão, Brazil.

Materials and methods: A cross-sectional study was conducted on 335 individuals who answered a questionnaire consisting of variables related to dental erosion. Afterwards, the individuals were subjected to clinical examinations and the basic erosive wear examination index was used to classify their teeth according to the presence and severity of dental erosion. Results: Descriptive statistics, the chi-square test, Poisson univariate and multivariate regression were performed at $5 \%$ level of significance. The sample was characterized by 204 females $(60.9 \%)$, the majority of whom were from 12 to 19 years of age $(78.5 \%)$, among whom $28.7 \%$ presented dental erosion. Their monthly family income was from 1 to 3 minimum wages $(56.4 \%)$. The variables that were significantly associated with the outcome were family income, chewing gum, and consumption of soft-drinks/juices before going to sleep ( $p=0.03$, $p=0.001$, and $p=0.04$, respectively). Individuals who chewed chewing gum were 2.27 times (95\% CI $=1.43-3.60)$ more likely to present dental erosion than those who did not chew gum. Individuals who ingested soft drinks or juices were 2.30 times $(95 \% \mathrm{CI}=1.30-4.10)$ more likely to present dental erosion.

Conclusion: The prevalence of erosion reflected the need for programs of prevention and guidance for patients about the etiological factors of the disease.

Keywords: young adults, dental erosion, prevalence, factors, tooth wear, life style

\section{Introduction}

During the last decade, there has been a significant increase in the presence of dental erosion in the young population due to changes in dietary, behavioral, and hygiene habits. This has resulted in an increasing number of non-carious lesions, particularly with reference to dental erosion, with rates of prevalence ranging from $1.8 \%$ to $34.1 \%$, preferentially affecting the palatal surfaces of maxillary anterior teeth and occlusal surfaces of mandibular first molars. ${ }^{1}$

The etiology of erosion is multifactorial, and mainly related to changes in contemporary lifestyle (dietary habits, ingestion of beverages, occupation, drugs, oral hygiene measures, and eating disorders); biological (general health, teeth, biofilm, acquired pellicle, and saliva), and chemical factors (buffer capacity of saliva, $\mathrm{pH}$, type of acid, presence of calcium, fluoride, and phosphorous), capable of interfering in the frequency and severity of erosive wear. ${ }^{2,3}$
Correspondence: Marco Aurélio Paschoa Post Graduate Program in Dentistry, CEUMA University, Renascença Campus, R. Josué Montello, 0I, 65075I20,

São Luís, Brazil

Email marcobpaschoal@hotmail.com 
Citrus fruits and soft drinks are consumed daily by youngsters who reside in cities in Northeastern Brazil that has a tropical climate and high temperatures, which are considered some of the etiological factors for erosion, but these are dependent on other associated factors. ${ }^{4}$

The prevalence of erosive lesions is intimately related to the type and time of exposure to an erosive agent, dental tissue mineralization, and saliva composition. ${ }^{5}$ A study conducted with young, physically active individuals, in comparison with non-active subjects revealed higher prevalence of erosive wear in individuals who practiced physical activities, due to the high consumption of citric fruits, sporting beverages, and changes in salivary flow associated with other factors. ${ }^{5}$ Furthermore, the erosive potential of foods and beverages is associated not only with their $\mathrm{pH}$ but also with the frequency, intensity, and manner of ingestion and with the proximity between ingestion of the acid food and tooth brushing. ${ }^{4,6}$

Among other factors, individuals who make constant use of medications that have a low $\mathrm{pH}$ and that come into direct contact with the tooth surface may present erosive potential, such as medications used by asthmatic patients who inhale vapors that mainly come onto contact with the palatine surfaces of the teeth.

Erosive lesions are clinically characterized by a smooth, dull, transparent surface, with an intact enamel edge in the gingival margin, loss of dental morphology, presence of depressions and concavities in the surfaces, presence of overlying restorations, and in severe cases the lesions may affect the dentin and pulp. ${ }^{8,9}$

Therefore, as with every health professional who has the primordial function of oral health promotion, dentists must be capable of diagnosing oral manifestations of systemic diseases because it is important for them to recognize the clinical signs of dental erosion, in association with a detailed anamnesis containing information about the patient for early identification of the lesion, and application of an ideal treatment plan with the purpose of reestablishing the individuals' health. ${ }^{9}$

Nowadays, investigating the prevalence of dental erosion in youngsters has become an interesting and feasible proposal, since this pathology requires special attention. Therefore, it is necessary to conduct studies for following up and preventing this wear, in order to collect data and monitor the condition when it is present, and thus serve as a guide to future approaches. ${ }^{10}$

Taking into consideration the foregoing discourse, the aim of the present study was to investigate the prevalence of and factors associated with dental erosion in individuals aged 12-30 years in a city in the Northeast of Brazil. Since there are no epidemiological surveys about dental erosion in this location, it is extremely important to conduct these surveys to recognize the local reality and, from their results, establish measures for reducing the risks to which children and young adults are exposed.

\section{Materials and methods Sample}

The present cross-sectional study, approved by the Research Ethics Committee of CEUMA University (\#1.489.871/2015), was conducted with 335 individuals of both genders, between 12 and 30 years of age, at the Dental Specialties Center (Centro de Especialidades Odontológicas) in the Northeast of Brazil. The participants or their guardians signed the free and informed term of consent and subsequently participated in the present investigation.

The exclusion criteria were as follows: individuals aged $<12$ years and $>30$ years; those who used orthodontic appliances because they made it difficult to perform clinical evaluation of the tooth surface. Criteria for inclusion in the study were as follows: only individuals attended at the Dental Specialties Center and patients who agreed to participate in the research.

\section{Sample calculation}

The sample size calculation was based on a study in which the random sample was composed of 502 adolescents. ${ }^{11}$ From this datum, a margin of error of 5\%, level of confidence of $95 \%$, and power of $80 \%$ were established. Considering the adjustment for finite populations (436 patients seen in a 6-month period at the Dental Office II of the Dental Specialties Center), a sample " $n$ " of 278 was obtained. To allow for possible losses, $20 \%$ was added, leading to a final "n" of 335 individuals.

\section{Application of questionnaire and clinical examination}

The questionnaire applied comprised questions about age, gender, family income, covering details of medical history, dietary, and behavioral habits of the individual. After application of the questionnaire, the patients were submitted to intraoral clinical examination. Before the examination, the evaluator was calibrated by means of images and clinical examination, in order to verify the reproducibility of the dental erosion diagnosis. Calibration consisted of 10 individuals examined twice, with an interval of 1 week between 
examinations, and the same individuals were not included in the main sample. Intra-examiner agreement was 0.83 (kappa).

The clinical examination was performed by a single examiner, in the dental office at the Center. First, the tooth surfaces received prophylaxis, and then, the basic erosive wear examination (BEWE) was used to classify the teeth with regard to the presence and severity of dental erosion. The degrees of severity or appearance of wear of the teeth were classified as: without loss of surface (0), initial loss of enamel surface texture (1), distinct defect or loss of hard tissue (dentin) in $<50 \%$ of the surface area (2), and loss of hard tissue in $>50 \%$ of the surface area (3). ${ }^{12}$

The vestibular, occlusal/incisal, palatine/lingual surfaces of all the teeth, except for third molars, were evaluated for dental erosion according to BEWE, but only the most severely affected surface for each sextant was recorded. After this, the scores obtained for the sextants were added up, and the individuals were classified with regard to the presence of erosion (BEWE score ranging from 1 to 18 ) and absence of erosion (BEWE score equal to 0 ), and as without risk (score 0-2), low-risk (3-8), medium-risk (9-13), or high-risk (14-18) for dental erosion.

The entire biosafety protocol was complied with when performing this clinical examination.

\section{Instructions to patients}

The individuals who participated in this research were given educational lectures that covered topics about the etiological factors of dental erosion and oral hygiene guidance. Individuals who were diagnosed with dental erosion received a weekly application of 5\% sodium fluoride varnish $(22,600$ ppm fluoride, Duraphat; Colgate Palmolive Company®, New York, NY, USA) applied with a microbrush and were referred to the Dental Specialties Center for the various treatments required.

\section{Statistical analysis}

Data analysis involved descriptive and inferential statistics.

Descriptive statistics was used to describe the sample and the distribution of erosion. The chi-square test was applied to evaluate association among the independent variables and the outcome (dental erosion). To investigate the explanatory factors for dental erosion, the Poisson regression with robust variance was performed. The independent variables that presented $p<0.20$ in the univariate model were inserted into the multivariate regression model. The level of significance adopted was 5\%. The software program SPSS for Windows, version 21.0 (IBM, Armonk, NY, USA), was used for the analyses.

\section{Results}

The majority of the sample was characterized by individuals of the female gender $(204 / 60.9 \%)$, young people aged $12-19$ years $(263 / 78.5 \%)$, monthly family income between 1 and 3 minimum wages (189/56.4\%). The majority of the individuals presented with absence of events were associated with the outcome studied (presence of dental erosion) (276/82.4\%), juice (315/94\%), citric fruit (195/58.2\%), soft drink (285/85.1\%), coffee (260/77.6\%), yogurt (238/71\%), vitamin $\mathrm{C}$ consumption (205/61.2\%), and chewing gum chew (233/69.6\%). Additionally, the presence of dental erosion was found in 96 individuals $(28.7 \%)$.

In relation to the scores of the index adopted, the authors verified that the male gender presented higher $(\%)$ values for the initial loss of enamel surface texture (score 1/30.5\%) and loss of hard tissue from the tooth surface (score $2 / 2.3 \%$ and $3 / 1.5 \%$ ) in comparison with the female gender (Table 1).

Family income, chewing on chewing gum, and consuming soft drink or juice before going to sleep were significantly associated with the frequency of dental erosion $(p<0.05$; Table 2).

Individuals who chewed chewing gum were 2.27 times (95\% CI $=1.43-3.60)$ more likely to present dental erosion than those who did not chew gum. Individuals who ingested soft drinks or juices were 2.30 times $(95 \% \mathrm{CI}=1.30-4.10)$ more likely to present dental erosion (Table 3 ).

In relation to the level of risk for dental erosion for the sample evaluated, the authors observed that $281(83.9 \%)$

Table I Total mean BEWE score and percentage of BEWE score for each gender and age groups $(n=335)$

\begin{tabular}{llllll}
\hline $\begin{array}{l}\text { Independent } \\
\text { variables }\end{array}$ & Mean BEWE (SD) & \% BEWE & & & Score 2 (\%) \\
\cline { 3 - 5 } & & Score 0 (\%) & Score I (\%) & Score 3 (\%) \\
\hline $\begin{array}{l}\text { Gender } \\
\text { Male }\end{array}$ & $1.06( \pm 2.04)$ & 65.6 & 30.5 & 2.3 & 1.5 \\
$\quad$ Female & $0.80( \pm 1.75)$ & 75.0 & 22.5 & 2.0 & 0.5 \\
Age group & & & & & \\
$\quad$ I2-19 years & $0.76( \pm 1.74)$ & 73.8 & 24.0 & 1.5 & 0.8 \\
$26-24$ years & $1.06( \pm 2.16)$ & 65.5 & 27.6 & 3.4 & 3.4 \\
$26-30$ years & $1.58( \pm 2.24)$ & 60.5 & 34.9 & 4.7 & 0.0 \\
\hline
\end{tabular}

Abbreviation: BEWE, basic erosive wear examination. 
Table 2 Distribution of frequency of individuals with and without dental erosion according to the independent variables $(n=335)$

\begin{tabular}{|c|c|c|c|}
\hline \multirow[t]{2}{*}{ Independent variables } & \multicolumn{3}{|c|}{ Dental erosion } \\
\hline & $\begin{array}{l}\text { No } \\
\text { n (\%) }\end{array}$ & $\begin{array}{l}\text { Yes } \\
\text { n (\%) }\end{array}$ & $p$-value \\
\hline Monthly family income & & & 0.033 \\
\hline I MWs & $94(78.3)$ & $26(21.7)$ & \\
\hline $\mathrm{I}-3 \mathrm{MWs}$ & $124(65.6)$ & $65(34.4)$ & \\
\hline $3 \mathrm{MWs}$ & $20(80.0)$ & $5(20.0)$ & \\
\hline Events with erosive potential & & & 0.106 \\
\hline Yes & $37(62.7)$ & $22.3(37.3)$ & \\
\hline Absence of diseases/conditions & $202(73.2)$ & $74(26.8)$ & \\
\hline Juice consumption & & & 0.518 \\
\hline Yes & $226(7 I .7)$ & $89(28.30)$ & \\
\hline No & $13(65.0)$ & $7(35.0)$ & \\
\hline Citrus fruit consumption & & & 0.134 \\
\hline Yes & $133(68.2)$ & $62(31.8)$ & \\
\hline No & $106(75.7)$ & $34(24.3)$ & \\
\hline Soft drink consumption & & & 0.911 \\
\hline Yes & $203(7 I .2)$ & $82(28.8)$ & \\
\hline No & $36(72.0)$ & $14(28.0)$ & \\
\hline Coffee consumption & & & 0.883 \\
\hline Yes & I86 (7I.5) & $74(28.5)$ & \\
\hline No & $53(70.7)$ & $22(29.3)$ & \\
\hline Yogurt consumption & & & 0.201 \\
\hline Yes & $165(69.3)$ & $73(30.7)$ & \\
\hline No & $74(76.3)$ & $23(23.7)$ & \\
\hline Vitamin $C$ consumption & & & 0.496 \\
\hline Yes & 149 (72.7) & $56(27.3)$ & \\
\hline No & $90(69.2)$ & $40(30.8)$ & \\
\hline Chewing gum & & & 0.001 \\
\hline Yes & $154(66.1)$ & 79 (33.9) & \\
\hline No & $85(83.3)$ & $17(16.7)$ & \\
\hline $\begin{array}{l}\text { Beverage ingested before going } \\
\text { to sleep }\end{array}$ & & & 0.044 \\
\hline Milk or water & $173(72.7)$ & $65(27.3)$ & \\
\hline Soft drink or juice & $7(43.8)$ & $9(56.3)$ & \\
\hline Does not drink & $59(72.8)$ & $22(27.2)$ & \\
\hline
\end{tabular}

Abbreviation: MWs, minimum wages.

presented no risk; 53 individuals (15.8\%) and 1 individual $(0.3 \%)$ presented low- and high-risk for erosion, respectively (Table 4).

\section{Discussion}

The authors verified that 96 individuals $(28.7 \%)$ of the sample researched presented some degree of dental erosion/ erosive dental wear. These data were related to the chewing on chewing gum, a common habit among adolescents in this age group, and to the consumption of soft drinks or citric juices before going to sleep, due to high temperatures found even at night. ${ }^{13}$

Data in the literature have demonstrated similar prevalence data of $27.3 \%$ of erosion in schoolchildren aged $12-13$ years in China. ${ }^{14} \mathrm{~A}$ Brazilian study verified a $21 \%$ prevalence of erosion in adolescents aged 15-19 years, preferentially occurring on the palatal surfaces of maxillary anterior teeth and on the occlusal surfaces of mandibular first molars. ${ }^{1}$ Another European investigation conducted in the same year verified that $42 \%$ of the population that was studied presented signs of erosion in 18-year-old youngsters, and of these, $13.4 \%$ presented signs of advanced dental wear, due to changes in lifestyle, dietary, and personal hygiene habits. ${ }^{9}$

According to contemporary studies, this condition was not restricted to adolescents, but a considerable portion of the child population also presented different degrees of dental erosion. ${ }^{15,16}$ As was the case with adolescents, there was frequent disagreement among the studies as regards prevalence data that ranged from $10 \%$ to $80 \%$ in primary dentition. ${ }^{17,18}$

In the present study, no differences were observed between the genders in relation to the prevalence of dental erosion. This variable seems to have little influence on the presence of the outcome studied. One study ${ }^{11}$ evaluated a sample of adolescents between the ages of 14 and 16 years ( 254 boys and 248 girls) confirming the results obtained in the present research. However, the present study was in disagreement with the results found in the study cited above, in which the prevalence of dental erosion was verified predominantly in the female gender in the ratio of 2.3:1 in comparison with the male gender. ${ }^{19}$

Relative to the variable age, the authors verified that the older the age, the greater the change in surface texture and loss of dental structure. This is due to the cumulative nature of wear, and because older individuals have had their teeth exposed to acid diets for a longer time, they presented more severe erosive lesions when compared with younger individuals..$^{20}$ This corroborated the findings of the present study, in which individuals aged 25-30 years obtained a higher percentage in the BEWE score when compared with that of the younger age groups.

The socioeconomic factor presented no influence on determining the presence of erosion, which was also found in another study. ${ }^{21}$ Similarly, whether they are healthy or not, dietary habits that include a high consumption rate of acidic foods may subject children of different socioeconomic origins to similar levels of risk for dental erosion. ${ }^{15}$ However, a monthly family income between 1 and 3 minimum wages was associated with the condition.

On the other hand, there seems to be a correlation between belonging to a higher socioeconomic level and less propensity for developing erosive lesions; this association (as yet inconclusive) deserves further investigation in order to determine its cause. ${ }^{11,14}$ 
Table 3 Poisson regression models explaining the influence of independent variables on dental erosion $(n=335)$

\begin{tabular}{|c|c|c|c|c|}
\hline Independent variables & $\begin{array}{l}\text { PR not adjusted } \\
(95 \% \mathrm{Cl})\end{array}$ & p-value & $\begin{array}{l}\text { PR adjusted } \\
(95 \% \mathrm{CI})^{\S}\end{array}$ & $p$-value \\
\hline \multicolumn{5}{|l|}{ Gender } \\
\hline Male & $1.374(0.982-1.922)$ & 0.06 & & \\
\hline Female & 1 & & & \\
\hline \multicolumn{5}{|l|}{ Age group } \\
\hline $26-30$ years & $1.507(0.989-2.297)$ & 0.05 & & \\
\hline $26-24$ years & $1.314(0.765-2.258)$ & 0.32 & & \\
\hline $12-19$ years & 1 & & & \\
\hline \multicolumn{5}{|l|}{ Family income } \\
\hline I MWs & $\mathrm{I} .083(0.46 \mathrm{I}-2.546)$ & 0.85 & & \\
\hline $\mathrm{I}-3 \mathrm{MWs}$ & $1.720(0.766-3.859)$ & 0.18 & & \\
\hline $3 \mathrm{MWs}$ & 1 & & & \\
\hline \multicolumn{5}{|l|}{ Events with erosive potential } \\
\hline Yes & 1.391 (0.947-2.042) & 0.09 & & \\
\hline No* & - & & & \\
\hline Absence of diseases/conditions & 1 & & & \\
\hline \multicolumn{5}{|l|}{ Juice consumption } \\
\hline Yes & $0.807(0.433-1.505)$ & 0.50 & & \\
\hline No & 1 & & & \\
\hline \multicolumn{5}{|l|}{ Citrus fruit consumption } \\
\hline Yes & $1.309(0.916-1.872)$ & 0.14 & $1.28(0.91-1.80)$ & 0.158 \\
\hline No & 1 & & 1 & \\
\hline \multicolumn{5}{|l|}{ Soft drink consumption } \\
\hline Yes & $1.028(0.635-1.662)$ & 0.91 & & \\
\hline No & 1 & & & \\
\hline \multicolumn{5}{|l|}{ Coffee consumption } \\
\hline Yes & $0.970(0.650-1.448)$ & 0.88 & & \\
\hline No & 1 & & & \\
\hline \multicolumn{5}{|l|}{ Yogurt consumption } \\
\hline Yes & $1.294(0.863-1.939)$ & 0.21 & & \\
\hline No & 1 & & & \\
\hline \multicolumn{5}{|l|}{ Vitamin $\mathrm{C}$ consumption } \\
\hline Yes & $0.888(0.631-1.249)$ & 0.49 & & \\
\hline No & 1 & & & \\
\hline \multicolumn{5}{|l|}{ Chew chewing gum } \\
\hline Yes & $2.034(1.272-3.253)$ & 0.00 & $2.26(1.43-3.60)$ & 0.001 \\
\hline No & $\mathrm{I}$ & & 1 & \\
\hline \multicolumn{5}{|l|}{ Drink for going to sleep } \\
\hline Milk or water & $1.01(0.666-1.519)$ & 0.97 & $1.10(0.73-1.67)$ & 0.625 \\
\hline Soft drink or juice & 2.07 (1.183-3.627) & 0.01 & $2.30(1.3-4.1)$ & 0.010 \\
\hline Does not drink & I & & 1 & \\
\hline
\end{tabular}

Notes: ${ }^{A}$ Adjustment for control variables (age, gender, monthly family income, and diseases/conditions with erosive potential). ${ }^{*}$ No individual reported disease/conditions without erosive potential.

Abbreviations: $\mathrm{Cl}$, confidence interval; MWs, minimum wages; $\mathrm{PR}$, prevalence ratio.

Table 4 BEWE level of risk for dental erosion $(n=335)$

\begin{tabular}{lll}
\hline Categories & \multicolumn{2}{l}{ Risk of erosion } \\
\cline { 2 - 3 } & $\mathbf{n}$ & $\%$ \\
\hline Without risk (0-2) & $28 \mathrm{I}$ & 83.9 \\
Low risk (3-8) & 53 & 15.8 \\
High risk (14-18) & $\mathrm{I}$ & 0.3 \\
Total & 335 & 100.0 \\
\hline
\end{tabular}

Abbreviation: BEWE, basic erosive wear examination.
Regarding the index used, BEWE is an accepted and adequate index to be used for epidemiological studies, as it is a simple tool, transferable with easy reproducibility, and a valid instrument to academic community in comparison to other indexes, such as Evaluating Index of Dental Erosion (EVIDE); Simplified Tooth Wear Index (STWI), both cited before that use different teeth calculation, and are less used. ${ }^{10-12}$

In the present study, there were no statistically significant associations with the presence of dental erosion for the 
majority of variables studied. This condition is not related to a single cause only, but is linked to a conjunction of factors that will make it possible for a lesion to develop. ${ }^{22}$ The authors were able to verify that the consumption of only citric fruits and juices, and similarly, the consumption of yogurt soft drinks and Vitamin $\mathrm{C}$ were not considered a risk factor for erosion. The protective factors of saliva, such as its buffering capacity and salivary flow; acquired pellicle and composition of tooth enamel may be as important as the frequency of exposure to acids, which may explain the absence of association between diet and erosion. ${ }^{1,23}$

After the regression analysis, an interesting data confirmed the erosive potential presented by chewing gum as a risk factor for the disease and also the habit of ingesting soft drinks/juices before going to sleep (Table 4). These data validated a study ${ }^{24}$ in which the authors affirmed that the acid filling of chewing gum associated with the abrasion, produced by the gum itself on the tooth surface and the dental wear that occurs during mastication were considered risk factors for erosion, promoting a significant change in the microhardness of tooth enamel. Furthermore, in the nocturnal period, there is a reduction in the production and flow of saliva that reduces the capacity for neutralizing the $\mathrm{pH}$ of the oral medium (dietary acids), contributing to the development of erosive lesions. This may be directly related to the consumption of soft drinks before going to sleep. ${ }^{4,25,26}$

Dental erosion in adolescents and young adults has become a significant problem. The strategy of offering preventive care must be implemented, including more campaigns that promote a healthier lifestyle for persons at risk for dental erosion. This reflects the need for adopting preventive measures by means of providing patients with guidance about the etiological factors of the disease.

\section{Limitations}

The present study had some limitations, such as the information collected by means of responses obtained from adolescents, and therefore, subject to memory bias. Moreover, there is no international agreement about the criteria for diagnosis of dental erosion. Therefore, further longitudinal population studies must be conducted with the purpose of following up these lesions over a long period of time.

\section{Conclusion}

In summary, the prevalence of dental erosion was $28.7 \%$ for the studied sample, irrespective of gender and age group. Erosion was associated with monthly family income, chewing on chewing gums and consumption of soft drinks or juices before going to sleep, which are considered risk factors for the condition studied.

\section{Acknowledgment}

This study was supported by FAPEMA (Fundação de Amparo à Pesquisa e Desenvolvimento Científico do Maranhão) PAEDT \#01916/15 and publication support.

\section{Author contributions}

Marco Aurelio Paschoal wrote the original draft and contributed to conceptualization, methodology, project administration, resources, supervision, and formal analysis. Meire Coelho Ferreira was involved with the conceptualization, methodology, results, statistics, and formal analysis. Luanda Luciano was committed to collection of data, entering the data for statistics paper writing, and editing of the draft. All authors contributed toward data analysis, drafting and critically revising the paper, and agreed to be accountable for all aspects of the work.

\section{Disclosure}

The authors report no conflicts of interest in this work.

\section{References}

1. Aguiar YPC, Santos FG, Moura EFF, et al. Association between dental erosion and diet in Brazilian adolescents aged from 15 to 19: a population based study. Sci World J. 2014;13(2):1-9.

2. Scaramucci T, Hara AT, Zero DT, Ferreira SS, Aoki IV, Sobral MAP. In vitro evaluation of the erosive potential of orange juice modified by food additives in enamel and dentine. J Dent. 2011;39:841-848.

3. Huysmans MCDNJ, Chew HP, Ellwood RP. Clinical studies of dental erosion and erosive wear. Caries Res. 2011;45 (Suppl 1):60-68.

4. Al-Majed I, Maguire A, Murray JJ. Prevalence and risk factors for dental erosion in 5-6 year-old and 12-14-year-old boys in Saudi Arabia. Comm Dent Oral Epidemiol. 2002;30:38-46.

5. Mulic A, Tveit AB, Songe D, Sivertsen H, Skaare AB. Dental erosive wear and salivary flow rate in physically active Young adults. BMC Oral Health. 2012;12(8):1-9.

6. Kato MT, Buzalaf MA. Iron supplementation reduces the erosive potential of a cola drink on enamel and dentin in situ. J Appl Oral Sci. 2012;20(3):318-22.

7. Thomas MS, Parolia A, Kundabala M, Vikram M. Asthma and oral health: a review. Aust Dent J. 2010;55:128-133.

8. Carvalho TS, Baumann T, Lussi A. Does erosion progress differently on teeth already presenting clinical signs of erosive tooth wear than on sound teeth? an in vitro pilot trial. BMC Oral Health. 2016;17:14.

9. Struzycka I, Rusyan E, Boguslawska-Kapala A. Prevalence of dental erosion in young adults aged 18 years in Poland. Przegl Epidemiol. 2014;68:689-693

10. Bartlett DW, Lussi A, West NX, Bouchard P, Sanz M, Bourgeois D. Prevalence of tooth wear on buccal and lingual surfaces and possible risk factors in young European adults. J Dent. 2013;41:1007-1013.

11. Margaritis V, Mamai-Homata E, Koletsi-Kounari H, Polychronopoulou A. Evaluation of three different scoring systems for dental erosion: a comparative study in adolescents. J Dent. 2011;39(1):88-93.

12. Bartlett D, Ganss C, Lussi A. Basic Erosive Wear Examination (BEWE): a new scoring system for scientific and clinical needs. Clin Oral Investig. 2008;12 (Suppl 1):65-68. 
13. Salas MMS, Nascimento GG, Ferreira FV, Tarquinio SBC, Huysmans MCDNJM, Demarco FF. Diet influenced tooth erosion prevalence in children and adolescents: results of a meta-analysis and meta-regression. J Dent. 2015;43(8):865-875.

14. Wang P, Lin HC, Chen JH, Liang HY. The prevalence of dental erosion and associated risk factors in 12-13-year-old school children in Southern China. BMC Public Health. 2010;10:1-9.

15. Mantonanaki M, Koletsi-Kounari H, Mamai-Homata E, Papaioannou W. Dental erosion prevalence and associated risk indicators among preschool children in Athens, Greece. Clin Oral Invest. 2012;17:585-593.

16. Al-ashtal AA, Anders Johansson A, Omar R, Johansson AA. Dental erosion in groups of Yemeni children and adolescents and the modification of an erosion partial recording system. Int J Paediatr Dent. 2016;1-10.

17. Taji S, Seow W. A Literature Review of dental erosion in children. Aust Dent J. 2010;55:358-367.

18. Zhang S, Chau AMH, Lo EC, Chu CH. Dental caries and erosion status of 12-year-old Hong Kong children. BMC Public Health. 2014;14:8.

19. Ramos LR, Dietlen FR, Troche JMR, et al. Dental erosion, an extraesophageal manifestation of gastroesophageal reflux disease. The experience of a center for digestive physiology in Southeastern Mexico. Rev Esp Enferm Dig. 2014;106(2):92-97.
20. Vered Y, Lussi A, Zini A, Gleitman JH, Cohen HDS. Dental erosive wear assessment among adolescents and adults utilizing the basic erosive wear examination(BEWE) scoring system. Clin Oral Invest. 2014;18:1985-1990.

21. Ferreira FV, Praetzel JR, Ardenghi TM. Prevalence of tooth erosion and associated factors in 11-14-year-old Brazilian schoolchildren. J Public Health Dent. 2011;71:6-12.

22. Staufenbiel I, Adam K, Deac A, Geurtsen W, Günay H. Influence of fruit consumption and fluoride application on the prevalence of caries and erosion in vegetarians a controlled clinical trial. Eur J Clin Nutr. 2015;69(10):1156-1160.

23. Uhlen MM, Tveit AB, Stenhagen KR, Mulic A. Self-induced vomiting and dental erosion - a clinical study. BMC Oral Health. 2014;14(92):1-9.

24. Bolan M, Ferreira MC, Vieira RS. Erosive effects of acidic centerchewing gum on primary and permanent enamel. J Indian Soc Pedod Prevent Dent. 2008;1:149-152.

25. Amoras DR, Corona SAM, Rodrigues JAL, Serra MC. Effect of beverages on bovine dental enamel subjected to erosive challenge with hydrochloric acid. Braz Dent J. 2012;23(4):1-6.

26. Corrêa MCCSF, Lercol MM, Cunha MLRS, Henry MACA. Salivary parameters and teeth erosions inpatients with gastroesophageal reflux disease. Arq Gastroenterol. 2012;49(3):1-7.
Clinical, Cosmetic and Investigational Dentistry

\section{Publish your work in this journal}

Clinical, Cosmetic and Investigational Dentistry is an international peer-reviewed, open access, online journal focusing on the latest clinical and experimental research in dentistry with specific emphasis on cosmetic interventions. Innovative developments in dental materials, techniques and devices that improve outcomes and patient satisfac-

\section{Dovepress}

tion and preference will be highlighted. The manuscript management system is completely online and includes a very quick and fair peerreview system, which is all easy to use. Visit http://www.dovepress. $\mathrm{com} /$ testimonials.php to read real quotes from published authors. 